\title{
Population dynamics of an ecologically important range-extender: kelp beds versus sea urchin barrens
}

\author{
S. D. Ling*, C. R. Johnson \\ School of Zoology and Tasmanian Aquaculture \& Fisheries Institute, University of Tasmania, Private Bag 5, \\ Hobart 7001, Australia
}

\begin{abstract}
The barrens-forming sea urchin Centrostephanus rodgersii (Diadematidae) has recently undergone poleward range-extension to Tasmania where grazing of diverse and economically important macroalgal beds has occurred. We compared growth, biometric, dietary and morphometric characteristics of $C$. rodgersii between macroalgal habitat and adjacent barrens to inform population dynamics of the sea urchin within the newly extended range. The age structure of $C$. rodgersii in macroalgal habitat and adjacent barrens is similar, suggesting that both habitats have been influenced by similar recruitment events. However, there are clear differences in body size, body mass, spine length and diet of sea urchins in the 2 habitat types. We identified 2 broad morphologies of C. rodgersii. The first is of relatively large size with thick test, rapid growth and short spines, that grazes macroalgal beds (macroalgal eco-morph). The second ecomorph persists on the barrens habitat and demonstrates smaller body size, slower growth and thinner test, with gut contents dominated by closely cropped filamentous and/or coralline algae; but occurs at higher density, possesses longer spines and appears to enhance the persistence stability of barrens habitat once it is formed (barrens ecomorph). Invading dense, swell-prone macroalgal habitat of eastern Tasmania, the phenotypic plasticity displayed by this sea urchin appears to be an important mechanism facilitating colonisation of reef habitats within the extension region. Importantly, habitat-specific patterns in population dynamics are broadly consistent with those observed from within the historical range, suggesting that patterns in macroalgal-sea urchin dynamics and the ecological importance of this species will be similar across the newly extended range.
\end{abstract}

KEY WORDS: Centrostephanus rodgersii · Climate change · Invasion · Morphology · Growth · Reproduction $\cdot$ Seaweed beds $\cdot$ Sea urchin barrens

Resale or republication not permitted without written consent of the publisher

\section{INTRODUCTION}

Climate change is predicted to have major impacts on the distribution of species in the worlds' oceans (Rosenzweig et al. 2007). As oceans warm, a reshuffling of species distributions towards the poles (e.g. Walther et al. 2002, Parmesan \& Yohe 2003) will lead to changes in biological interactions which may in turn lead to major shifts in coastal ecosystems, particularly if ecologically dominant species undergo range modification (e.g. Hughes 2000, Harley et al. 2006). While many species are known to play dominant functional roles in particular coastal ecosystems (e.g. Andrew \& Byrne 2001, Steneck et al. 2002, Micheli \& Halpern
2005), the dynamics of such species and their ecological significance at higher latitudes is speculative. While species-specific and/or regional idiosyncrasies are likely, understanding the population dynamics and function of such species within new ranges will be essential to anticipate broader ecosystem responses.

Driven by a changing regional climate, the diadematid sea urchin Centrostephanus rodgersii (Agassiz) has undergone recent poleward (southern) range extension from southeast mainland Australia to Tasmania (Johnson et al. 2005, Ling et al. 2008, Ling et al. in press). Invading dense and productive macroalgal beds, incursion of $C$. rodgersii in Tasmania is important given the species' ability to catastrophically overgraze 
algal-dominated habitat, which results in widespread and persistent sea urchin barrens throughout the species' historical range in New South Wales (NSW) (reviewed by Andrew \& Byrne 2001). Indeed, such is the dominant ecological effect of $C$. rodgersii that, within its historical range, the sea urchin has formed and maintains barrens over approximately $50 \%$ of all near-shore rocky reefs (Andrew \& O'Neill 2000).

Since its first detection on the Tasmanian mainland coast in 1978, the sea urchin's abundance has increased, and evidence of barren areas now occur in some Tasmanian locations (Johnson et al. 2005). The potential for broad-scale ecological shifts from luxuriant macroalgal beds to sea urchin barrens in Tasmania therefore poses a major threat to local biodiversity and valuable reef-based fisheries that depend on macroalgal habitat (Johnson et al. 2005, Ling 2008). Hence, understanding the characteristics of Centrostephanus rodgersii populations leading to barrens formation and the expression of such characters on reefs within the extension-region is therefore important in assessing the ecological role of this sea urchin within Tasmania.

From studies in NSW, it is clear that a threshold density of Centrostephanus rodgersii is required to initiate widespread destructive grazing of macroalgae, and that this density is greater than that necessary to maintain barrens (Andrew \& Underwood 1993, Hill et al. 2003). As is typical among diadematids, C. rodgersii is nocturnal and displays a homing behavior so that localized grazed patches are manifest as halos radiating from crevices used for daytime shelter (reviewed by Andrew \& Byrne 2001). Importantly, the 'catastrophic shift' (after Scheffer et al. 2001) from small grazed patches $(<1-10 \mathrm{~s}$ of $\mathrm{m})$ to widespread barrens (100s of $\mathrm{m}$ ) occurs when localized grazed patches coalesce (Andrew 1993, Andrew \& Underwood 1993, Hill et al. 2003). Thus, C. rodgersii forms barrens in a different way to that documented for most other sea urchins (e.g. Strongylocentrotid species), which typically aggregate to form highly destructive mobile feeding fronts (e.g. Lang \& Mann 1976, Lauzon-Guay \& Scheibling 2007). Although the predominant mode of C. rodgersii barrens formation hinges on the use of localised shelter (a feature that makes barrens formation by this species highly predictable) populations maintaining widespread barrens in NSW and Tasmania do occur on featureless flat-rock habitat, indicating that shelter is not obligatory for $C$. rodgersii to form barrens (Andrew 1993, Andrew \& Byrne 2001, Johnson et al. 2005).

While widespread barrens currently occur in relatively few places in eastern Tasmania, the major feature of Centrostephanus rodgersii grazing on this coast is the occurrence of small barren patches within dense macroalgal beds, a condition referred to as incipient barrens (Johnson et al. 2005). Indeed, widespread barrens are currently only observed in northeastern Tasmania (including the Kent Group in eastern Bass Strait), while incipient barrens can be found across the east coast but have not been reported in southern Tasmania, where the sea urchin is rare and only occurs as scattered individuals (Johnson et al. 2005). Within the NSW range, boundaries between $C$. rodgersii barrens and macroalgal habitat demonstrate high stability and often align with discontinuities in reef substratum type, or with the sweeping motion of large brown seaweeds that can create an abrasive 'whiplash' effect on the benthos that appears to restrict the distribution of the sea urchin (e.g. Andrew 1993, Andrew \& Byrne 2001; also see Konar 2000). However, such a pattern of stability between macroalgal boundaries and barren habitat does not account for many sites in Tasmania where grazed patches display sharp boundaries on reefs with otherwise continuous rocky substratum. Furthermore, grazed areas on Tasmanian reefs are currently observed in relatively deep water $(>10 \mathrm{~m})$ (Johnson et al. 2005) compared to that observed within the historic range of $C$. rodgersii, where the barrens habitat extends across relatively shallow reefs $(<5 \mathrm{~m})$ (Andrew \& Byrne 2001).

The recent nature of the Centrostephanus rodgersii range extension and an increasing occurrence of grazing in Tasmania suggest that the sea urchin may have the capability to form widespread barrens over much of this coastline (Johnson et al. 2005). Clearly, the potential for expansion of $C$. rodgersii barrens in Tasmania, either by grazing at the edges of recently formed barrens or coalescence of smaller incipient barrens patches, is dependent on the dynamics of sea urchins at the boundaries of macroalgal habitat coupled with the dynamics of individuals maintaining previously grazed areas. Because demographic transitions of sea urchin populations may inform the dynamics of overgrazing (e.g. Lang \& Mann 1976, Kenner 1992, Pederson \& Johnson 2008), we investigated population dynamics of $C$. rodgersii within its new range by comparing the growth, biometric, dietary and morphometric characteristics of sea urchins on recently formed barrens with those existing within macroalgal boundaries. Observed dynamics are discussed with respect to well documented patterns from within the species' historic range.

\section{MATERIALS AND METHODS}

Study sites. We conducted the research in northeastern Tasmania at St. Helens, where there are recently formed Centrostephanus rodgersii barrens and transitional zones between barrens and macroalgal beds 
(hereafter 'macroalgal boundary habitat'). Further south, C. rodgersii inhabiting incipient barrens were examined at 3 sites: Freycinet Peninsula, Maria Island and Tasman Peninsula (Fig. 1). At St. Helens, the average density $( \pm \mathrm{SE}$ ) of Centrostephanus rodgersii on barrens $\left(2.09 \pm 0.1 \mathrm{~m}^{-2} ; 10\right.$ to $20 \mathrm{~m}$ depth) was higher than that within adjacent macroalgal boundary habitat $\left(1.61 \pm 0.2 \mathrm{~m}^{-2}\right.$; 8 to $12 \mathrm{~m}$ depth) or that within the interior of macroalgal beds where density declined rapidly $\left(0.36 \pm 0.2 \mathrm{~m}^{-2} ; 8\right.$ to $20 \mathrm{~m}$ depth). For incipient barrens patches at the 3 southern sites (15 to $20 \mathrm{~m}$ depth), average $C$. rodgersii density within patches ranged from $\sim 1.5$ to $3 \mathrm{~m}^{-2}$ (Johnson et al. 2005). As observed in some parts of the sea urchin's NSW range, subtidal macroalgal beds on the exposed eastern Tasmanian coast were dominated by Phyllospora comosa (Seirococcaceae) ( $\sim 3$ to $15 \mathrm{~m}$ depth) and/or Ecklonia radiata (Laminariales) ( 8 to $20 \mathrm{~m}$ depth), which typically form an algal canopy reaching $\sim 1$ to $2 \mathrm{~m}$ in height above the reef surface.

Growth, size and age structure. Habitat-specific growth models were derived by analysis of annual growth increments of tagged sea urchins. Sea urchin age-structure was then estimated for each habitat using the growth models to predict age-at-size for large numbers of individuals (Table 1). Individuals were tagged with tetracycline, and growth increment data was obtained from the change in length of jaw structures (demipyramids). Because demipyramids (jaws) of sea urchins grow continuously throughout a sea urchin's lifetime, and the growing edge stains readily with tetracycline, jaws provide a suitable structure to assess growth under field conditions (after Ebert 2001, 2004, Pederson \& Johnson 2008). For each of 2 sites near St. Helens (Fig. 1), sea urchins ranging from 61 to $133 \mathrm{~mm}$ test diameter (TD) were obtained from recently formed barrens and adjacent macroalgal boundary habitat by divers thoroughly searching and collecting all urchins from a randomly positioned plot (approximately $8 \times 8 \mathrm{~m}$ ) within each habitat until approximately 300 ind. were obtained (Table 1). At the surface, each individual was tagged by injection of 2 to $4 \mathrm{ml}$ (depending on size) of tetracycline-HCL (conc. $20 \mathrm{~g} \mathrm{l}^{-1}$ seawater) through the peristomial membrane. This dosage provided consistently readable tags in pilot field trials. Tagged urchins were returned promptly to the permanently marked experimental plots and allowed to grow for at least 12 mo before attempts to recover tagged individuals were made by collecting all sea urchins from within the plots and to $5 \mathrm{~m}$ outside their boundary to account for any movement of sea urchins out of the experimental plot during the sea urchins 'time at liberty', i.e. $1 \mathrm{yr}$ (Table 1).
Fig. 1. Study sites in Tasmania, southeastern Australia. At both sites near St. Helens, Centrostephanus rodgersii were sampled from recently formed barrens and adjacent macroalgal boundary habitat. At the 3 southern sites, C. rodgersii were sampled from incipient barrens

Table 1. Centrostephanus rodgersii. Tetracycline tagging in barrens and macroalgal boundary habitat at St. Helens, northeastern Tasmania. Growth models were generated from growth increment data standardised at 365 d growth. Dates are dd/mm/yyyy

\begin{tabular}{|lcccrrrr|}
\hline Habitat & Site & $\begin{array}{c}\text { No. } \\
\text { tagged }\end{array}$ & $\begin{array}{c}\text { Tagging } \\
\text { date }\end{array}$ & $\begin{array}{c}\text { Recovery } \\
\text { date }\end{array}$ & $\begin{array}{c}\text { Days at } \\
\text { liberty }\end{array}$ & $\begin{array}{c}\text { No. urchins } \\
\text { collected }\end{array}$ & $\begin{array}{c}\text { No. tags } \\
\text { recovered }\end{array}$ \\
\hline Macroalgal boundary & Elephant Rock & 341 & $28 / 07 / 2004$ & $22 / 09 / 2005$ & 421 & 731 & 153 \\
Macroalgal boundary & St. Helens Is. & 383 & $17 / 08 / 2004$ & $11 / 10 / 2005$ & 420 & 660 & 89 \\
Barren & Elephant Rock & 315 & $26 / 07 / 2004$ & $28 / 07 / 2005$ & 367 & 654 & 101 \\
Barren & St. Helens Is. & 283 & $29 / 07 / 2004$ & $29 / 07 / 2005$ & 365 & 679 & 74 \\
Total & & 1322 & & & & 2724 & 417 \\
\hline
\end{tabular}


Preparation of jaws and measurement of growth increments. Prior to removing jaw structures, the TD of each individual was measured using knife-edge vernier calipers. The complete Aristotle's lantern was removed, labelled and soaked in $12.5 \%$ sodium hypochlorite for $48 \mathrm{hr}$ to dissolve connective tissue and expose individual jaw structures; these were then dried and checked under UV light for the presence of a fluorescing tetracycline tag. For each tagged individual, a jaw growth increment $(\Delta L)$ was estimated by measuring (to $0.05 \mathrm{~mm}$ ) the distance from the inside edge of the fluorescing band to the growing aboral edge of the jaw with an ocular micrometer under $20 \times$ magnification. Jaw length at time of recapture $\left(L_{t+\Delta t}\right)$ was measured (to $0.1 \mathrm{~mm}$ ) using knife-edge vernier calipers. Estimated jaw length at time of tagging $\left(L_{t}\right)$ was calculated by subtracting the growth increment $(\Delta L)$ from jaw length at time of recapture $\left(L_{t+\Delta t}-\Delta L\right)$.

Selection and fitting of growth models. For tagrecaptured Centrostephanus rodgersii in eastern Tasmania, the pattern of annual jaw growth increment $(\Delta L)$ versus initial jaw size at tagging $\left(L_{t}\right)$ indicated an indeterminate growth pattern best described by an inverse logistic function. Optimum fits for the inverse logistic functions were determined by minimising the sum of the negative log-likelihoods for each of the observed growth increments $(\Delta L)$ and the expected growth increments derived by the model. The expected variation around the growth increments was explicitly modelled as a power function of the expected length (see Haddon et al. 2008).

The inverse logistic equation is written as:

$$
\Delta L=\frac{\operatorname{Max} \Delta L \times \Delta_{t}}{1+\mathrm{e}^{\operatorname{Ln}(19) \frac{\left(L_{t}-L_{50}^{m}\right)}{\left(L_{95}^{m}-L_{50}^{m}\right)}}}+\varepsilon_{L_{t}}
$$

where $\operatorname{Max} \Delta L$ is the hypothetical asymptotic maximum jaw growth increment at some initial size of sea urchin that sets the exponential term to zero; $\Delta_{t}$ is the actual time increment between tagging and recovery, i.e. $\sim 1 \mathrm{yr}_{;} L_{t}$ is the size when first tagged; $L_{50}^{m}$ is the initial length at which the mid-way point between the $\operatorname{Max} \Delta L$ and zero growth increment is reached; $L_{95}^{m}$ denotes the initial length at which $95 \%$ of the difference between zero and maximum increment is reached; and $\operatorname{Ln}(19)$ is a scaling parameter that defines the $L_{95}^{m}$ point. The error term $\varepsilon_{L t}$ is additive and normal, and assumed to have a mean of zero and SD of $\sigma_{L_{t^{\prime}}}$ which is also defined as a function of predicted length. The SD of the residual for each $L_{t}$ was modelled as a power function of the expected growth increment with 2 parameters $\alpha$ and $\beta$ (Haddon et al. 2008):

$$
\sigma_{L_{t}}=\alpha\left(\Delta \hat{L}_{t}\right)^{\beta}
$$

Biometrics and morphometrics. To assess the morphological characteristics of Centrostephanus rodgersii in barrens and macroalgal boundary habitat, 5 mass characters and 4 linear morphological dimensions were measured. It was necessary to track temporal patterns in some variables that varied seasonally, e.g. gonad weight. Mass characteristics for macroalgal boundary and widespread barrens habitats at St. Helens were sampled on 5 occasions over a $\sim 12$ mo period (ca. 2.5 mo intervals) between March 2004 and April 2005. On each sampling occasion, 30 C. rodgersii in the size range of $\sim 80$ to $110 \mathrm{~mm}$ TD (to reduce potential size related biases in body indices, M. Byrne pers. comm.) were collected by divers from each site. All animals were dissected fresh and drained of coelomic fluid and any free-surface water, and component body parts were weighed individually, viz. gonads, test and spines, gut plus gut contents, and Aristotle's lantern. Reproductive investment was described by the gonad index (GI) calculated as the percentage of an individual's total body weight that was gonad. Gut index (GutI) was similarly calculated as the percentage of total body weight as gut plus gut contents. The relative abundance of different gut contents were scored by assessing the planar percentage cover of pellet types spread evenly across a dissecting dish (8 $\mathrm{cm}$ radius). Seasonally invariate mass characters, i.e. test weights (plus spines) and lantern weights, were pooled across sampling periods. An estimate of $C$. rodgersii biomass per $\mathrm{m}^{2}$ of reef was obtained for each habitat type by multiplying the weight of the average-sized sea urchin (drained of coleomic fluid) for each habitat by the density of sea urchins within each habitat.

Linear morphological dimensions of TD, test height, jaw length and longest spine length were measured with knife-edge vernier calipers to the nearest $\mathrm{mm}$. Because the Centrostephanus rodgersii spine canopy consistently forms an even hemisphere, the length of the longest spine provided a useful index of overall spine morphology, i.e. the next 50 longest spines were on average $82 \%( \pm 0.6 \% \mathrm{SE})$ of the longest spine length $(n=28$, where $n$ is the number of individual sea urchins that were measured for 50 spine lengths). Test thickness (at ambitus) was estimated using a micrometer (to $0.1 \mathrm{~mm}$ ) clamped either side of the flat ambulacral plate.

Analyses. Growth curves between each habitat-site combination were compared using likelihood ratio tests, after Haddon (2001). All other statistical analyses were undertaken using $\mathrm{SAS}^{\circledR}$ software (v. 9.1). For ANOVA, data were checked for conformity to assumptions of homoscedasticity and normality. Where data were heteroscedastic, the transformation to stabilise variances was determined by the relationship between group SDs and means (Draper \& Smith 1981). Transfor- 
mations are expressed in terms of the untransformed variate, $Y$. Where appropriate, ANCOVA was undertaken by first testing for homogeneity of slopes among sites. If homogeneity of slopes was indicated, analysis proceeded to compare intercepts. Unless stated otherwise, the ANOVA/ANCOVA model had 2 main factors of Habitat (fixed) and Site (random), and the mean square of Habitat $\times$ Site was used to test the significance of Habitat. Frequency distributions were compared between habitats and sites by a series of Kolmogorov-Smirnov tests with an appropriate level of protection against type I error for non-orthogonal tests by adjusting $\alpha$ using the Dunn-Sidak method.

\section{RESULTS}

\section{Growth}

Annual growth of Centrostephanus rodgersii jaws was significantly faster in the macroalgal boundary habitat than in recently formed barrens (Figs. 2a,b). Likelihood-ratio tests revealed that growth models were significantly different between habitats ( $\mathrm{p}<$ 0.0001 ), but not among sites within habitats (macroalgal, $\mathrm{p}=0.67$; barrens, $\mathrm{p}=0.054$ ), thus growth for each habitat was modelled using data pooled within habitat type. Optimal inverse logistic growth parameters for C. rodgersii in macroalgal boundary habitat was $\operatorname{Max} \Delta L=2.622, L_{50}^{m}=17.369, L_{95}^{m}=27.663$ (for Eq. 1); and $\alpha=0.284, \beta=0.451$ (Eq. 2); for $C$. rodgersii existing on barrens $\operatorname{Max} \Delta L=5.448, L_{50}^{m}=12.104, L_{95}^{m}=23.259$ (Eq. 1); and $\alpha=0.265, \beta=0.490$ (Eq. 2). Size structure of $C$. rodgersii within macroalgal boundary habitat was bimodal and skewed towards larger individuals relative to that of adjacent barrens, which consisted of a unimodal distribution dominated by intermediatesized individuals (Fig. 3a). Jaw length frequency distributions showed broad similarity between habitats (Fig. 3b) and conversion of jaw lengths to age (using habitat-specific growth models) revealed broadly similar ages between barrens and macroalgal boundary habitats (Fig. 3c).

\section{Biometrics}

Temporal patterns in Centrostephanus rodgersii body indices show that GIs were generally higher within macroalgal boundary habitat relative to barrens; however, this difference was not significant during the peak of the spawning period (2-way Model III ANOVA: Habitat, $F_{1,1}=76.87, \mathrm{p}=0.072$; Site, $F_{1,116}=$ 1.67, $\mathrm{p}=0.200$; Habitat $\times$ Site, $F_{1,116}=0.15, \mathrm{p}=0.704$ ) (Fig. 4a). GutIs were generally higher for $C$. rodgersii
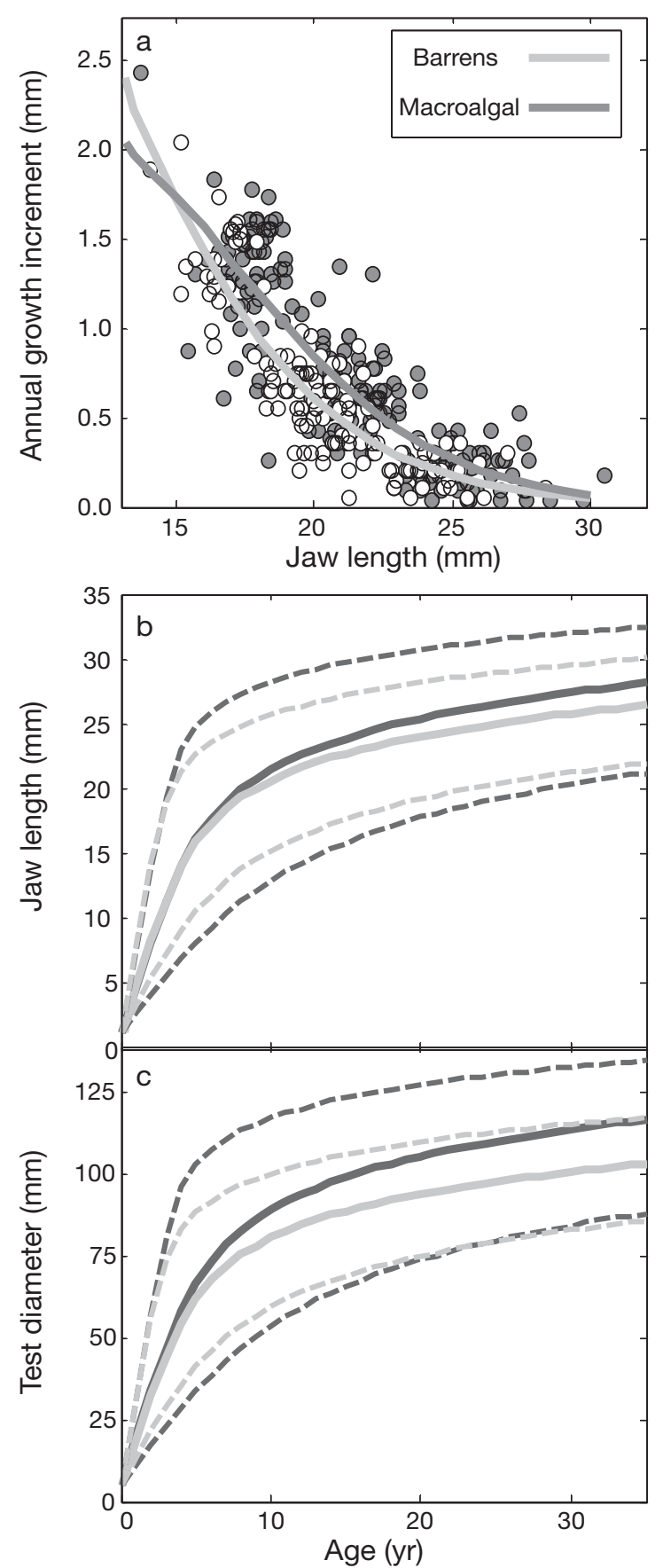

Fig. 2. Centrostephanus rodgersii. (a) Annual jaw growth increments for sea urchins in recently formed barrens and macroalgal boundary habitat. Jaw growth was best described by inverse logistic equations in both the macroalgal boundary habitat $(\bigcirc)$ and barrens (O). (b) Growth curves for sea urchin jaws. (c) Growth curves by test diameter (TD) obtained using habitat-specific conversion between TD and jaw length (macroalgal: $\mathrm{TD}=4.14 \mathrm{jaw} L, \mathrm{R}^{2}=0.66$; barrens: $\mathrm{TD}=$ 3.90jaw $\left.L, \mathrm{R}^{2}=0.78\right)$. (---) Respective $95 \%$ CIs obtained by bootstrap resampling 1000 times. Due to lack of data for small size classes (<13 mm jaw length), juvenile growth was standardised across habitats using the optimal $\operatorname{Max} \Delta L$ for all data pooled across habitats 

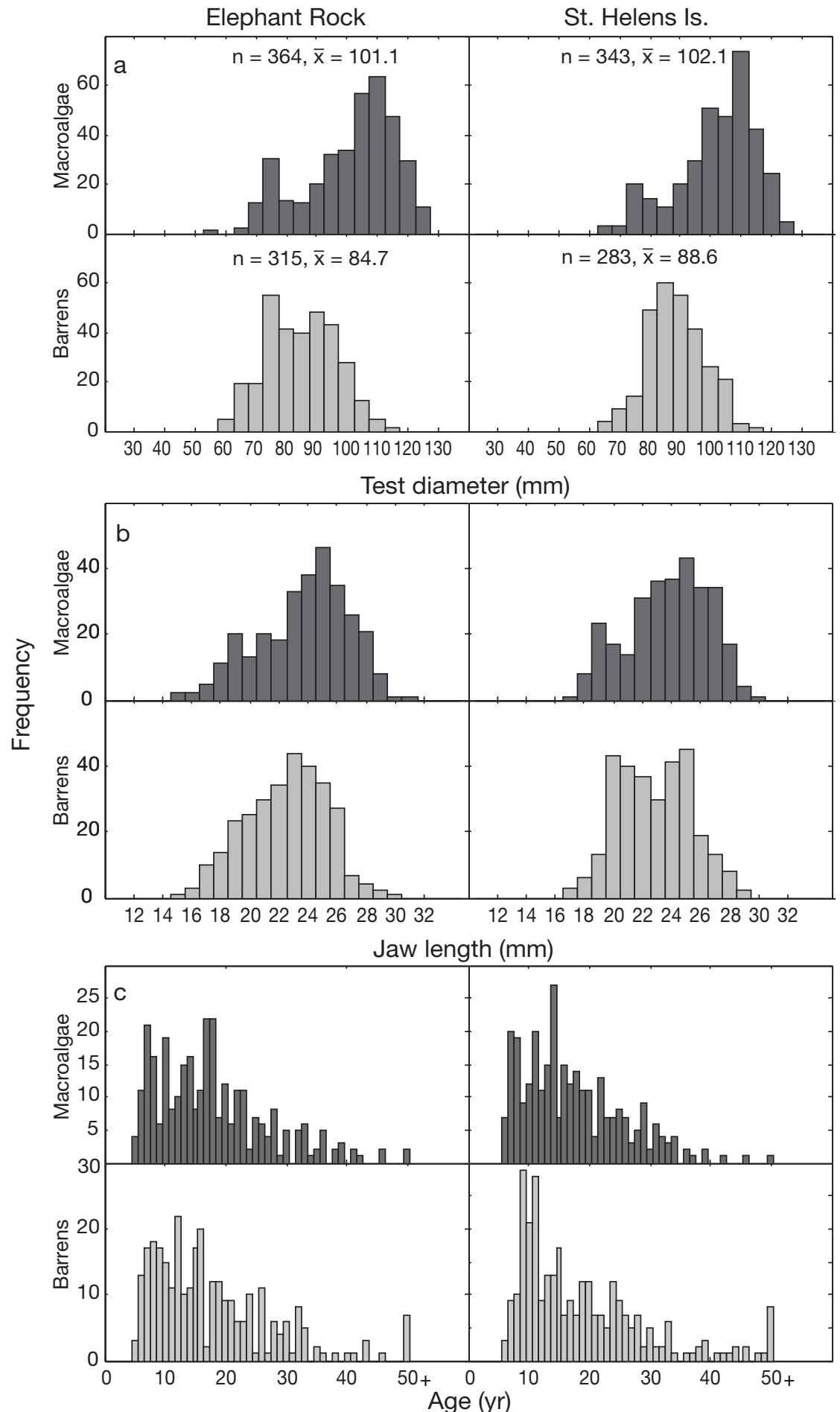

Fig. 3. Centrostephanus rodgersii. Test diameter (TD), jaw length and age frequencies on recently formed barrens and adjacent macroalgal boundary habitat. (a) TD frequency at time of tagging in 2004; all pair-wise Kolmogorov-Smirnov comparisons yielded significant differences, except for comparison of urchins from macroalgal habitat at the 2 sites (Dunn-Sidak adjusted $\alpha=0.0085, p=0.68$ ). (b) Jaw length frequency in 2005, n = 300 per habitat/site combination. (c) Age frequency estimated from jaw lengths using the appropriate habitat-specific growth function (see Fig. 2b) adjusted for age as at 11/10/2005 (see Table 1), $\mathrm{n}=300$ per habitat/site combination. Comparison of age frequencies revealed non-significant differences in age distributions between all samples $(\mathrm{K}-\mathrm{S}$ tests minimum $\mathrm{p}=0.12)$ in macroalgal boundary habitat yearround, and comparison of elevated GutIs during the post-spawning period revealed a significant habitat effect (Habitat, $F_{1,1}=191.23, \mathrm{p}=0.046$; Site, $F_{1,116}=32.04 \mathrm{p}=<0.0001$; Habitat $\times$ Site, $F_{1,116}=0.53, \mathrm{p}=0.467$ ) (Fig. $4 \mathrm{~b}$ ). Gut contents of $C$. rodgersii at macroalgal boundaries consistently contained greater proportions of fleshy macroalgal material relative to urchins from barrens that predominantly contained filamentous and encrusting algal material (post-spawning period revealed a significant interaction: $Y^{0.68}, F_{1,116}=$ 7.38, $\mathrm{p}=0.008$ ) (Fig. 4c). The mean biomass of $C$. rodgersii occurring within macroalgal boundary habitat (546.86 \pm $91.46 \mathrm{~g} \mathrm{~m}^{-2}$, mean $\pm \mathrm{SE}$ ) was not significantly different to that in adjacent barrens $\left(453.62 \pm 166.28 \mathrm{~g} \mathrm{~m}^{-2}\right)$ (1-way ANOVA, $\left.F_{1,2}=0.24, \mathrm{p}=0.67\right)$.

\section{Morphometrics}

On average, Centrostephanus rodgersii from recently formed barrens possessed longer jaws for a given TD compared to urchins from macroalgal boundary habitat; slopes varied across habitats $\left(F_{\text {calc }(3,1192)}=3.26, \mathrm{p}<0.001\right)$, but were homogenous within each habitat type (barrens, $F_{1,596}=1.88, \mathrm{p}=$ 0.17; macroalgal boundary, $F_{1,596}=$ 0.00, p = 0.96) (Fig. 5a). Conversely, total body weight, hereafter 'body weight' (test weight plus spines) of $C$. rodgersii (including spines) was significantly heavier on average within macroalgal boundary habitat relative to animals of similar TD on the barrens. However, there was also significant variability in relative body weight among sites and among habitats across sites (Model II, 2-way ANCOVA: test for homogeneity of slopes, $F_{\text {calc }(3,592)}=$ 0.89, p > 0.25; Habitat, $F_{1,1}=115.07, \mathrm{p}<$ 0.0001 ; Site, $F_{1,1}=31.09, \mathrm{p}<0.0001$; Habitat $\times$ Site, $F_{1,595}=9.43, \mathrm{p}=0.002$ ) (Fig. 5b). Examination of relationships between test height and test diameter revealed heterogeneous slopes between samples (test for homogeneity of slopes, $\left.F_{\text {calc }(3,1192)}=3.26, \mathrm{p}<0.025\right)$; 


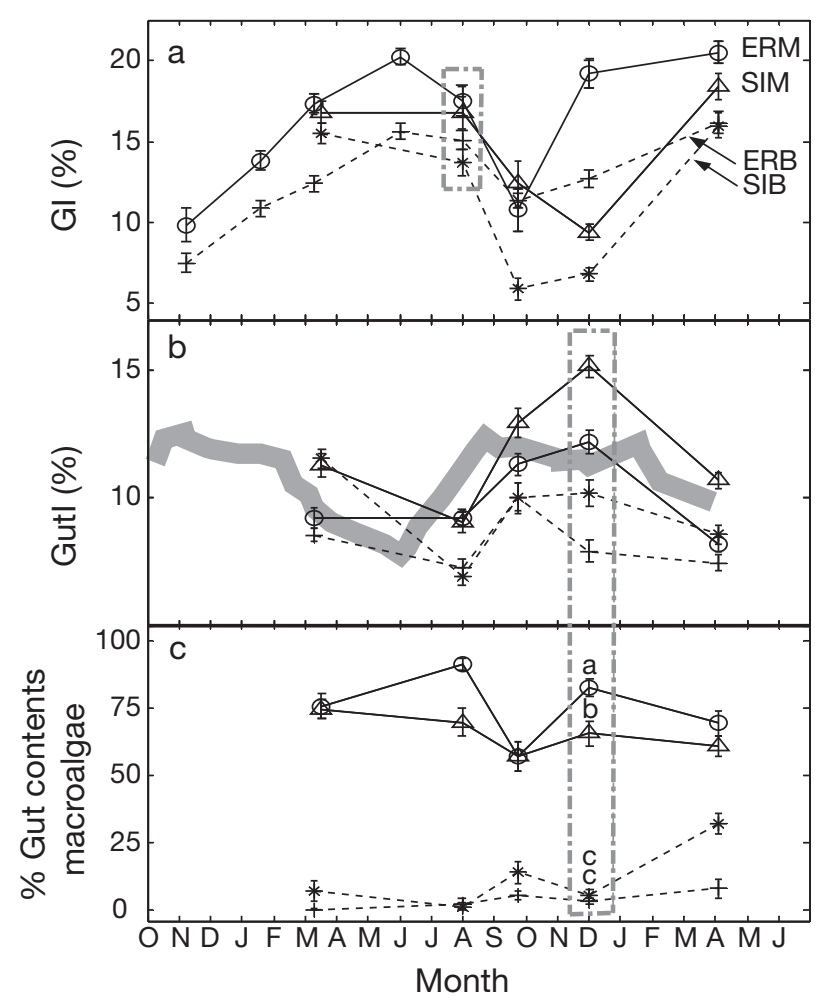

Fig. 4. Centrostephanus rodgersii. Temporal pattern of body indices within recently formed barrens and macroalgal boundary habitat, 2004 to 2005. Data are means \pm SE $(n=30)$. (-) Macroalgal boundary: (O) Elephant Rock Macroalgal $(\mathrm{ERM}) ;(\triangle)$ St. Helens Is Macroalgal (SIM). (---) Barrens: (+) Elephant Rock Barren (ERB); $(*)$ St. Helens Island Barren (SIB). (a) Gonad indices (GI); (---) pre-spawning peak. (b) Gut indices (GI); ( $\square$ ) gut index cycle obtained across 3 additional sites in eastern Tasmania (see Ling et al. 2008); (- -) post-spawning period. (c) Gut contents; habitat by site REGWQ (Ryan-Einot-Gabriel-Welsch multiple range test) groupings for the post-spawning period (-•-) are indicated by different letters, $\alpha=0.05$

however, there was a high degree of overlap between fitted trend lines, indicating little evidence for habitat specific patterns in test height (Fig. 5c). Heavier body weights, corrected for TD, within the macroalgal boundary habitat was explained by these urchins having relatively thicker tests than their counterparts on barrens (1-way ANCOVA: test for homogeneity of slopes, $F_{1,84}=0.01, \mathrm{p}=0.94 ;$ Habitat, $F_{1,85}=21.69, \mathrm{p}<$ 0.0001) (Fig. 5d).

Spine length relative to TD was generally longer for sea urchins from the open barrens than those within the macroalgal boundary zone. Across habitats, spine length for Centrostephanus rodgersii generally increased with increasing TD to about $70 \mathrm{~mm}$, and thereafter a slight increase in spine length was observed for urchins from barrens, but spine length declined with increase in TD for individuals from macroalgal bound-

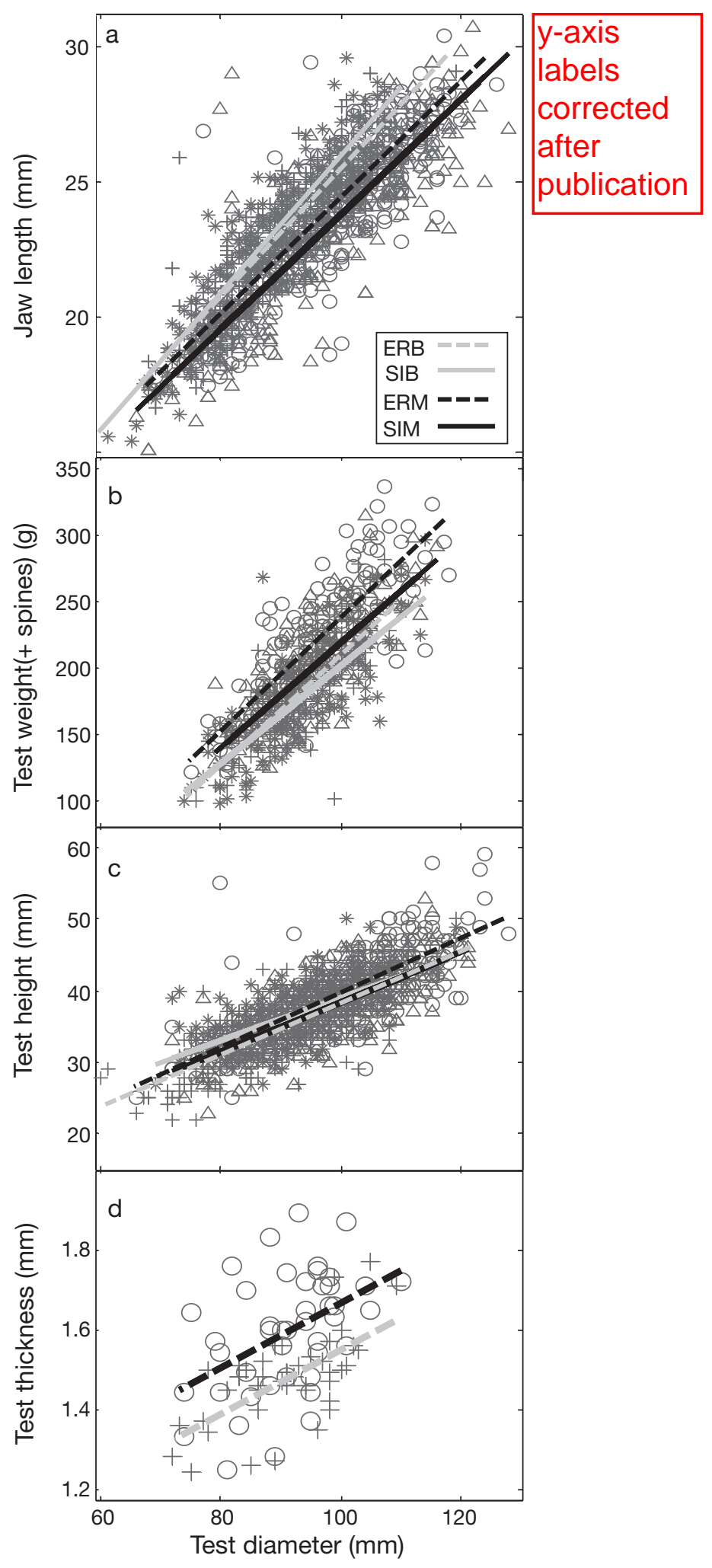

Fig. 5. Centrostephanus rodgersii. Jaw and test characteristics within macroalgal boundary (black trendlines) and barrens (grey trendlines) $\mathrm{n}=300$ except for $(\mathrm{d})$, where $\mathrm{n}=44$. Symbols as for Fig. 4. (a,b,c,d) Jaw length, weight of test + spines, test height and test thickness vs. test diameter 


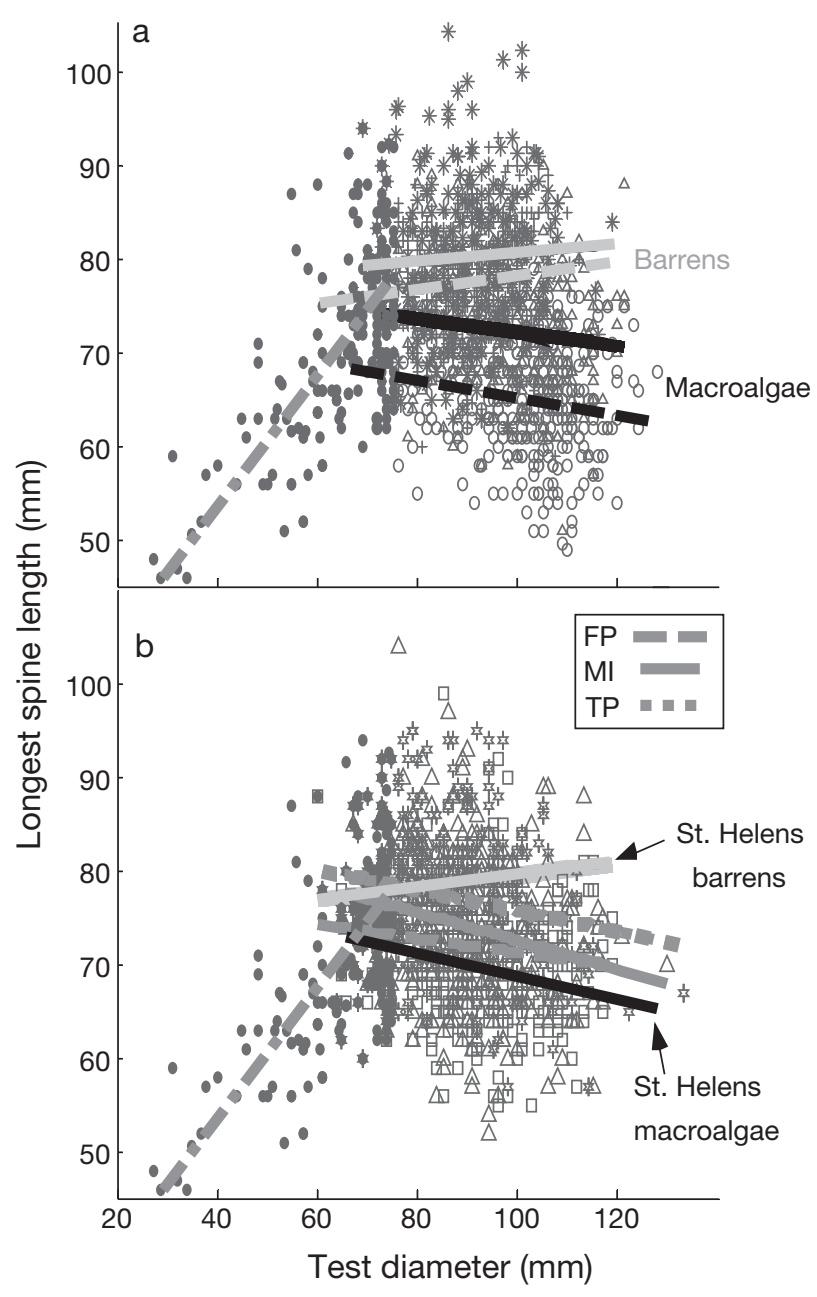

Fig. 6. Centrostephanus rodgersii. Longest spine length vs. test diameter (TD) in recently formed barrens and macroalgal habitat. (a) Macroalgal boundary and barrens at St. Helens; symbols and trend lines as for previous figures; $(0)$ additional data for smaller size classes of $C$. rodgersii $(<75 \mathrm{~mm})$ obtained across eastern Tasmania; ( $\square$ - $)_{\text {) }}$ trendline fitted to these data. (b) Incipient barrens relative to trends at St. Helens. ( $\square$ ) Freycinet Peninsula (FP), $\mathrm{n}=345 ;(\triangle)$ Maria Island (MI), $\mathrm{n}=353$; (후) Tasman Peninsula (TP), $\mathrm{n}=288$; trendlines for St. Helens based on data pooled within each habitat type $(n=600$, datapoints for these samples not shown)

ary habitat, indicating net spine erosion through time (Fig. 6a). For sea urchins from St. Helens (>75 mm TD), a comparison of longest spine vs. TD yielded significantly different slopes between samples (test for homogeneity of slopes, $\left.F_{\text {calc }(3,1192)}=4.75, \mathrm{p}<0.001\right)$, however slopes were not detectably different within habitat type (barrens, $F_{1,596}=0.36, \mathrm{p}=0.55$; macroalgal, $F_{1,596}$ $=0.30, \mathrm{p}=0.58)$. Consistent with the pattern of spine erosion observed at macroalgal boundaries at St. Helens, C. rodgersii from incipient barrens further to the south in eastern Tasmania displayed a similar negative relationship between spine length and TD; slopes
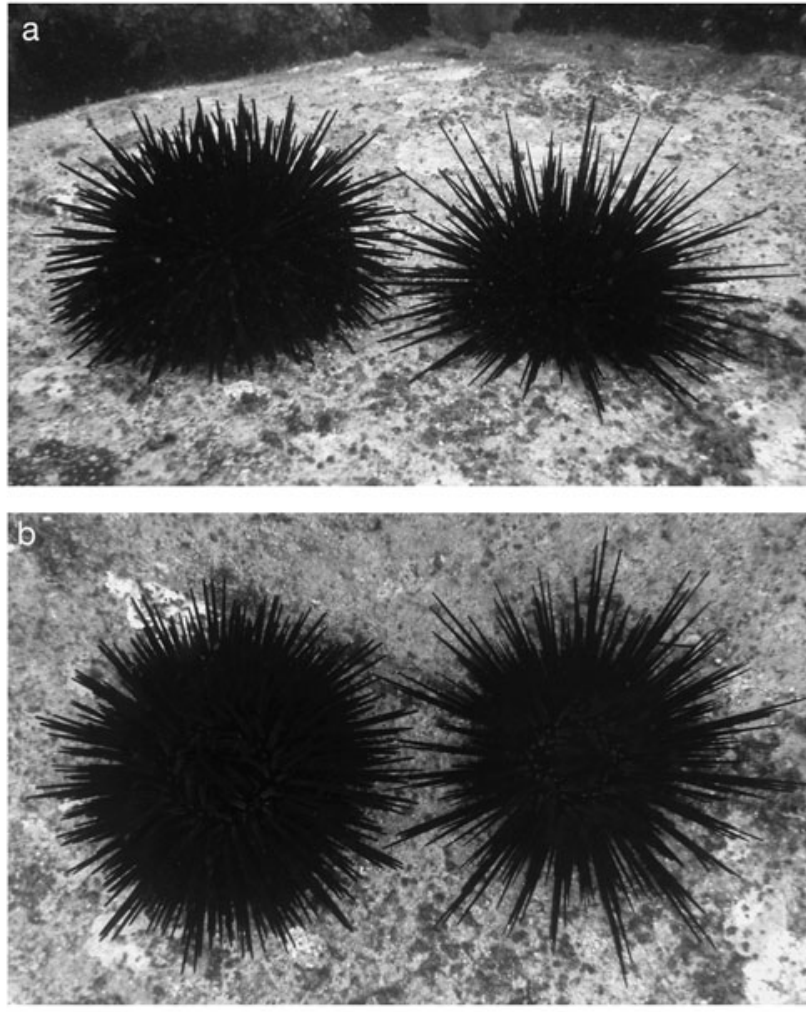

Fig. 7. Centrostephanus rodgersii. Typical specimens from macroalgal boundary habitat (lefthand side, test diameter $[\mathrm{TD}]=110 \mathrm{~mm}$ ) and recently formed barrens (righthand side, $\mathrm{TD}=82 \mathrm{~mm}$ ). (a) Oblique view; (b) aboral view. Individuals were collected from adjacent habitat states at $10 \mathrm{~m}$ depth. Although the TD is $28 \mathrm{~mm}$ smaller for the barrens specimen, the diameter of the spine canopy is greater than that of the larger individual from within the macroalgal boundary habitat. The estimated age for the displayed individual from the macroalgal boundary habitat is $\sim 30 \mathrm{yr}$, while the individual from the barrens is $\sim 12 \mathrm{yr}$

of spine length vs. TD for urchins from incipient barrens and macroalgal boundary samples were all negative and not statistically different from each other $\left(F_{3,1578}=0.86, \mathrm{p}=0.46\right)$. Conversely, for widespread barrens, spine length was positively related to TD, and this slope was statistically different to the negative slopes described for urchins from incipient barrens $\left(F_{3,1578}=8.67, \mathrm{p}<0.0001\right)$ (Fig. 6b). Differences in spine morphology between $C$. rodgersii residing on open barrens and in macroalgal habitat were visually obvious in situ (Fig. 7).

\section{DISCUSSION}

\section{Growth, diet and morphology}

Similar age-structure of Centrostephanus rodgersii in macroalgae boundary habitat and on recently 
formed barrens suggests that both habitats are influenced by broadly similar recruitment events, and there is no pronounced ontogenetic shift in habitat preferences. Importantly, the emergence of distinctive growth and phenotypic patterns between the alternative reef states indicates persistence of $C$. rodgersii within each habitat and limited exchange of individuals across this habitat interface (e.g. Konar 2000). Consistent with observations of C. rodgersii within its historical range in NSW (Blount 2004), and with sea urchins in other systems (e.g. Rowley 1990, Meidel \& Schiebling 1999), C. rodgersii grew significantly faster within macroalgal habitat in eastern Tasmania. Faster growth of $C$. rodgersii within macroalgal habitat was consistent with relatively heavy gut weights and a diet composed predominantly of fleshy macroalgae. In adjacent barrens, the smaller, slower growing sea urchins displayed lower gut weights for a given size and a diet of predominantly filamentous and encrusting coralline algae with fleshy macroalgae consumed only occasionally, a result consistent with studies elsewhere (e.g. Harrold \& Reed 1985). The persistence of sea urchins on reefs where algae has been heavily grazed is clearly dependent on the ability of sea urchins to switch their diet from fleshy macroalgae to filamentous and/or coralline algae (reviewed by Johnson \& Mann 1982). However, in contrast to many other studies (e.g. Lang \& Mann 1976, Johnson \& Mann 1982, Meidel \& Schiebling 1998), including the pattern demonstrated by C. rodgersii in NSW (Byrne et al. 1998), habitat-related patterns in nutritional status were not reflected as strong contrasts in GI. This intriguing result indicates that individuals on recently formed barrens in eastern Tasmania obtained sufficient nourishment to invest strongly in reproduction, but appeared to do so at the expense of somatic growth. Because population densities of $C$. rodgersii on Tasmanian barrens ( 1 to $2 \mathrm{~m}^{-2}$ ) were 2 to 4 times lower than in NSW (Johnson et al. 2005), reduced competition between individuals for food may explain the greater than expected GIs on recently formed Tasmanian barrens, as described for other systems (e.g. Wahle \& Peckham 1999).

Intriguingly, the biomass density of Centrostephanus rodgersii $\left(\mathrm{g} \mathrm{m}^{-2}\right)$ was not significantly different between macroalgal boundary habitat and barrens; however, the sea urchin was more numerous per unit biomass on the barrens. This pattern is typically observed in NSW, where C. rodgersii densities on barrens are approximately twice that found within fringing macroalgal habitat (Underwood et al. 1991, Andrew \& Byrne 2001, Blount 2004). Our observation of lower densities of $C$. rodgersii within macroalgal habitat but similar age-structure to that on adjacent barrens, suggests greater rates of settlement and/or post-settlement sur- vivorship in heavily grazed habitats. Within their historical range, it has been suggested that settlement rates are higher on barrens than in seaweed beds (Andrew 1991, Blount 2004); however, we were unable to sample recently settled $C$. rodgersii to test this idea (it was not possible to access the interstices of the reef where they reside). Accumulation of animals at the barrensmacroalga interface as a result of increased mobility of urchins on barrens (Mattison et al. 1977, Lauzon-Guay \& Scheibling 2007) is unlikely to be a contributing mechanism because $C$. rodgersii does not form feeding fronts.

Consistent with contrasting growth rates of Centrostephanus rodgersii across the alternative habitat states, comparisons of relative jaw length and test thickness (both of which are indicators of foodlimitation in sea urchins; Ebert 1980, Black et al. 1982, 1984) also revealed clear differences between habitats. C. rodgersii from recently formed Tasmanian barrens possessed longer jaws, but thinner tests, for a given test diameter relative to sea urchins in macroalgal boundary habitat, consistent with studies from the sea urchin's historical range (Andrew \& Byrne 2001, Blount 2004). Individuals from macroalgal habitat also had shorter spines for a given test diameter than their counterparts on adjacent barrens, reflecting that they are subject to abrasion and breakage by the sweeping action of robust macroalgae (S. D. Ling pers. obs.). Thus, broadly distinctive phenotypes of C. rodgersii emerged from within the extension-region; sea urchins with a large and thick test but relatively small Aristotle's lantern and short spines were observed to forage among macroalgae; while sea urchins from barrens possessed relatively small and thin tests, but large jaws and longer spines.

\section{Informing macroalgal-urchin dynamics within the newly extended range}

While juvenile canopy-forming algae and foliose understory species are highly susceptible to sea urchin grazing, under some circumstances large adult algae, particularly canopy-forming species such as Phyllospora comosa and Ecklonia radiata (found in both NSW and eastern Tasmania), appear to have a partial size refuge from Centrostephanus rodgersii (Andrew \& Byrne 2001, Hill et al. 2003). Under the influence of ocean surge typical of the exposed Tasmanian coastline, large macroalgae appear particularly immune to sea urchin grazing by restricting the distribution of urchins with robust, yet flexible lamina that create a whiplash effect on the benthos (e.g. Himmelman 1980, Vasquez \& McPeak 1998, Konar 2000, Gagnon et al. 2003). Thus, invasion of mature Tasmanian macroalgal 
beds and persistence of $C$. rodgersii within this habitat may become difficult under surge conditions. Indeed, the domination of shallow, exposed Tasmanian reefs by dense, mature stands of macroalgae (i.e. P. comosa, which is commonly found to depths of $\sim 10 \mathrm{~m}$ ) emerges as a likely factor influencing the currently deep (>10 m) depth distribution of $C$. rodgersii on this coast (Johnson et al. 2005).

The presence of adult macroalgae also appeared to influence the morphology of Centrostephanus rodgersii as the short-spined configuration was particularly striking where individuals were bound to crevices within the range of whiplash from macroalgal fronds (see Fig. 7). Indeed, in other work we observed that long-spined C. rodgersii from barrens, when held in cages with large macroalgae, all displayed short spines after $\sim 6$ mo (S. D. Ling pers. obs.). Conversely, short-spined individuals from macroalgal habitat began to regrow length in their spines (observed as pale growing tips) when held in aquaria free of macroalgae abrasion for several months (also observed for Strongylocentrotus franciscanus, RogersBennett et al. 1995). Furthermore, short-spined $C$. rodgersii also possessed thicker and heavier tests than their long-spined counterparts. Consistent with this pattern, spine breakage in $S$. purpuratus results in greater overall rates of calcification resulting in thicker, heavier and more robust tests (at the expense of regrowth in spine length) arguably better suited to exposed coastal conditions (Edwards \& Ebert 1991). Thus, plastic resource allocation would appear capable of shifting to favour persistence within exposed macroalgal dominated habitats.

Importantly, the final transition from macroalgal beds to Centrostephanus rodgersii barrens appears to occur when large, mature plants, often weakened by grazing of haptera (S. D. Ling pers. obs.), either break away during surge or senesce (e.g. Harrold \& Reed 1985, Tegner et al. 1995). Thus, providing $C$. rodgersii can persist within swell-prone macroalgal habitat, eventual felling of large robust plants may allow barrens to expand into shallower reef margins ( $<10 \mathrm{~m}$ depth) as commonly observed within the species' historical range (e.g. Andrew 1993, Andrew \& Byrne 2001). Indeed, overgrazing by C. rodgersii within its new range is associated with relatively mature sea urchin populations, as widespread barrens are only currently observed at sites where the average population age is $>18$ yr (Fig. 8). Such a pattern suggests a time delay between the incursion of the sea urchin and the onset of barren formation, indicating that if populations are able to grow, then patterns of grazing within the extension region may converge on that observed within the species' historical range.

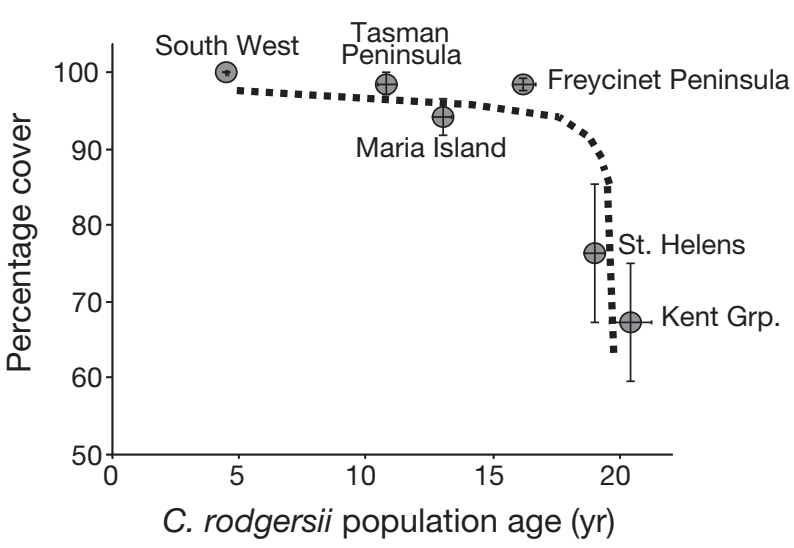

Fig. 8. Centrostephanus rodgersii. Cover of canopy-forming macroalgae vs. mean population age on rocky reefs across the range-extension region; data are means \pm SE. Macroalgal cover data for eastern Tasmania is for reefs 5-18 $\mathrm{m}$ depth (after Johnson et al. 2005); for southwest Tasmania only 3 C. rodgersii individuals and no barrens have been reported, hence the luxuriant macroalgal cover observed across this region was considered to constitute $100 \%$. Mean population age estimated for each location from jaw lengths of 300 ind., except for the Kent Group and southwest Tasmania, where age was estimated from test diameters $(n=273$ and $n=3$ respectively), data from Ling et al. (in press). (.-.): Thresholdtype relationship, fitted by eye

\section{Barren formation and range expansion}

In creating a habitat free of large and potentially 'inhibitory' macroalgae, formation of barrens by Centrostephanus rodgersii, while resulting in reduced individual performance through lower food availability, may manifest as a net positive feedback at the population level (e.g. Jones et al. 1997, Scheffer et al. 2001). That is, C. rodgersii may be considered to facilitate its own invasion success in eastern Tasmania by modifying the macroalgal habitat and effectively 'paving the way' for further establishment of high density sea urchin populations (Breen \& Mann 1976, Lang \& Mann 1976, Himmelman 1980, Tegner 1980, Tegner \& Dayton 1981, Miller et al. 2007). Indeed, Mann \& Breen (1972) first hypothesised that observations of increased sea urchin abundance associated with barrens may indicate that the creation of barrens facilitates urchin population expansion. Since then, this possibility has received little focus (but see Lang \& Mann 1976). Rather, emphasis has been placed on the negative effects of barrens at the individual level, even though the formation of barrens has been documented to enhance localised carrying capacity (Lang \& Mann 1976, Himmelman 1980), post-settlement survival (Rowley 1989), population stability and recruitment (e.g. Andrew \& Byrne 2001), and enhance population level reproductive success by spatially aggregating 
free-spawning sea urchins (e.g. Wahle \& Peckham 1999).

Because a greater number of individuals may exist on barrens for a given biomass of sea urchins, overgrazing of large and abrasive macroalgal plants on swell-prone reefs appears to be a mechanism by which sea urchins may establish highly abundant populations. In the case of a range-extending sea urchin occurring at relatively low population size at a range margin (where risk of local extinction may be high), the conversion of macroalgal-dominated reef to sea urchin barrens therefore appears to be an important invasion process facilitating the establishment of viable populations. Population stability of sea urchins may also be increased by minimising individual predation risk. Because long spines appear to confer greater resistance against predators, predation risk to Centrostephanus rodgersii is seemingly lower on barrens where individuals can afford relatively long spines. Based on habitat specific growth models (Fig. 2c) and measures of size-specific lobster predation (S. D. Ling unpubl. data), the short-spined morph of C. rodgersii occurring in macroalgal habitat takes on average 21 yr to reach a size refuge from all but the very largest lobsters. In contrast, the long-spined morph of C. rodgersii characteristic of barrens, even though it has slower growth in test diameter, develops a spine canopy allowing predatory size refuge much quicker at $\sim 15$ yr.

\section{CONCLUSIONS}

Within the extension region, habitat-specific patterns of Centrostephanus rodgersii were broadly consistent with that observed from within its historic range. This suggests that the dominant ecological role and ecological dynamics of the species will be conserved across its extended range. A notable contrast, however, was the exceptional reproductive status of sea urchins within recently formed barrens. Nonetheless, because individual gonad production is known to vary in a density-dependent manner among sea urchins (e.g. Byrne et al. 1998, Blount 2004), this result suggests that if population size were to increase within the extension region then habitat-specific contrasts in reproductive condition would converge on that observed within the species' historical range. Indeed, further coastal warming predicted for Tasmania (reviewed by Poloczanska et al. 2007) appears set to facilitate further population expansion of C. rodgersii (Ling et al. 2008, Ling et al. in press), thus the ecological importance of the sea urchin in this system is likely to increase. Finally, because of the typically low functional diversity observed across temperate rocky reef ecosystems (e.g. Steneck et al. 2002, Micheli \& Halpern 2005), our results indicate that the climate-driven addition of functionally important species to higher latitudes can result in major changes to the dynamics of temperate marine systems.

Acknowledgements. We thank S. Talbot, A. Reid, D. Stevenson, L. Lyall, R. Downie, J. and R. Stuart-Smith and R. Magierowski for their assistance with urchin tagging and tag recovery. $\mathrm{H}$. Pederson provided valuable advice on tagging procedures and growth analysis. M. Haddon assisted with the development of growth models. This research was supported by funds awarded to C.R.J. from UTas and the Tasmanian Aquaculture and Fisheries Institute. S.D.L. was supported by the UTas-CSIRO Joint PhD Program in Quantitative Marine Science. The manuscript was improved by comments from J. Lauzon-Guay, J. Stuart-Smith and 2 anonymous reviewers.

\section{LITERATURE CITED}

Andrew NL (1991) Changes in subtidal habitat following mass mortality of sea urchins in Botany Bay, New South Wales. Aust J Ecol 16:353-362

Andrew NL (1993) Spatial heterogeneity, sea urchin grazing, and habitat structure on reefs in temperate Australia. Ecology 74:292-302

Andrew NL, Byrne M (2001) The ecology of Centrostephanus rodgersii. In: Lawrence JM (ed) Edible sea urchins: biology and ecology. Elsevier Science, New York, p 149-160

Andrew NL, O'Neill AL (2000) Large-scale patterns in habitat structure on subtidal rocky reefs in New South Wales. Mar Freshw Res 51:255-263

Andrew NL, Underwood AJ (1993) Density-dependent foraging in the sea urchin Centrostephanus rodgersii on shallow subtidal reefs in New South Wales, Australia. Mar Ecol Prog Ser 99:89-98

Black R, Johnson MS, Trendall JT (1982) Relative size of Aristotle's lantern in Echinometra mathaei occurring at different densities. Mar Biol 71:101-106

Black R, Codd C, Hebbert S, Vink S, Burt J (1984) The functional significance of the relative size of Aristotle's llantern in the sea urchin Echinometra mathaei (de Blainville). J Exp Mar Biol Ecol 77:81-97

Blount C (2004) Density-dependent aspects of the ecology of the sea urchin Centrostephanus rodgersii. PhD Thesis, University of Sydney

Breen PA, Mann KH (1976) Destructive grazing of kelp by sea urchins in eastern Canada. J Fish Res Board Can 33: 1278-1283

Byrne M, Andrew NL, Worthington DG, Brett PA (1998) Reproduction in the diadematoid sea urchin Centrostephanus rodgersii in contrasting habitats along the coast of New South Wales, Australia. Mar Biol 132:305-318

Draper N, Smith H (1981) Applied regression analysis. Wiley, New York

Ebert TA (1980) Relative growth of sea urchin jaws: an example of plastic resource allocation. Bull Mar Sci 30:467-474

Ebert TA (2001) Growth and survival of post-settlement sea urchins. In: Lawrence JM (ed) Edible sea urchins: biology and ecology. Elsevier, New York, p 79-102

Ebert TA (2004) Shrinking sea urchins and the problems of measurement. In: Heinzeller T, Nebelsick JH (eds) Echinoderms: München. Proc 11th Int Echinoderm Conf, Munich, Germany, 6-10 October 2003. Taylor \& Francis 
Group, London, p 321-325

Edwards PB, Ebert TA (1991) Plastic responses to limited food availability and spine damage in the sea urchin Strongylocentrotus purpuratus. J Exp Mar Biol Ecol 145:205-220

Gagnon P, Himmelman JH, Johnson LE (2003) Algal colonization in urchin barrens: defense by association during recruitment of the brown alga Agarum cribrosum. J Exp Mar Biol Ecol 290:179-196

Haddon M (2001) Modelling and quantitative methods in fisheries. Chapman \& Hall/CRC, Boca Raton, FL

Haddon M, Mundy C, Tarbath D (2008) Using an InverseLogistic model to describe Tasmanian blacklip abalone (Halitotis rubra) growth increments. Fish Bull 106:58-71

> Harley CDG, Hughes RA, Hultgren KM, Miner BG and others (2006) The impact of climate change in coastal marine systems. Ecol Lett 9:228-241

Harrold C, Reed DC (1985) Food availability, sea urchin grazing and kelp forest community structure. Ecology 66: 1160-1169

Hill NA, Blount C, Poore AGB, Worthington D, Steinberg P (2003) Grazing effects of the sea urchin Centrostephanus rodgersii in two contrasting rocky reef habitats: effects of urchin density and its implications for the fishery. Mar Freshw Res 54:691-700

Himmelman JH (1980) The role of the green sea urchin, Strongylocentrotus broebachiensis, in the rocky subtidal region of Newfoundland. In: Pringle JD, Sharp GJ, Caddy JF (eds) Proceedings of the workshop on the relationship between sea urchin grazing and commercial plant/animal harvesting. Can Tech Rep Fish Aquat Sci 954:92-119

Hughes L (2000) Biological consequences of global warming: Is the signal already apparent across natural systems? Trends Ecol Evol 15:56-61

Johnson CR, Mann KH (1982) Adaptations of Strongylocentrotus droebachiensis for survival on barren grounds in Nova Scotia. In: Lawrence JM (ed) Echinoderms: Proc Int Conf, Tampa Bay, 14-17 September 1981. CRC Press, Boca Raton, FL, p 277-283

Johnson CR, Ling SD, Ross J, Shepherd S, Miller K (2005) Establishment of the long-spined sea urchin (Centrostephanus rodgersii) in Tasmania: first assessment of potential threats to fisheries. Project No. 2001/044, Final Report, Fisheries Research and Development Corporation. University of Tasmania, Hobart

Jones CG, Lawton JH, Shachak M (1997) Positive and negative effects of organisms as physical ecosystem engineers. Ecology 78:1946-1957

> Kenner MC (1992) Population dynamics of the sea urchin Strongylocentrotus purpuratus in a Central California kelp forest: recruitment, mortality, growth, and diet. Mar Biol 112:107-118

Konar B (2000) Seasonal inhibitory effects of marine plants on sea urchins: structuring communities the algal way. Oecologia 125:208-217

Lang C, Mann KH (1976) Changes in sea urchin populations after the destruction of kelp beds. Mar Biol 36:321-326

> Lauzon-Guay J, Scheibling RE (2007) Behaviour of sea urchin Strongylocentrotus droebachiensis grazing fronts: foodmediated aggregation and density-dependent facilitation. Mar Ecol Prog Ser 329:191-204

Ling SD (2008) Range expansion of a habitat-modifying species leads to loss of taxonomic diversity: a new and impoverished reef state. Oecologia 156:883-894

Ling SD, Johnson CR, Frusher S, King CK (2008) Reproductive potential of a marine ecosystem engineer at the edge of a newly expanded range. Glob Change Biol 14:907-915

Ling SD, Johnson CR, Ridgway K, Hobday AJ, Haddon M (in press) Climate-driven range extension of a sea urchin: inferring future trends by analysis of recent population dynamics. Glob Change Biol, doi: 10.1111/j.1365-2486. 2008.01734.x

Mann KH, Breen PA (1972) The relation between lobster abundance, sea urchins, and kelp beds. J Fish Res Board Can 29:603-605

Mattison JE, Trent JD, Shanks AL, Akin TB, Pearse JS (1977) Movement and feeding activity of red sea urchins (Strongylocentrotus franciscanus) adjacent to a kelp forest. Mar Biol 39:25-30

- Meidel SK, Schiebling RE (1998) Annual reproductive cycle of the green sea urchin, Strongylocentrotus droebachiensis, in differing habitats in Nova Scotia, Canada. Mar Biol 131:461-478

$>$ Meidel SK, Schiebling RE (1999) Effects of food type and ration on reproductive maturation and growth of the sea urchin Strongylocentrotus droebachiensis. Mar Biol 134: 155-166

> Micheli F, Halpern BS (2005) Low functional redundancy in coastal marine assemblages. Ecol Lett 8:391-400

Miller RJ, Adams AJ, Ebersole JP, Ruiz E (2007) Evidence for positive density-dependent effects in recovering Diadema antillarum populations. J Exp Mar Biol Ecol 349:215-222

Parmesan C, Yohe G (2003) A globally coherent fingerprint of climate change. Nature 421:37-42

> Pederson HG, Johnson CR (2008) Growth and age structure of sea urchins (Heliocidaris erythrogramma) in complex barrens and native macroalgal beds in eastern Tasmania. ICES J Mar Sci 65:1-11

Poloczanska ES, Babcock RC, Butler A, Hobday AJ and others (2007) Climate change and Australian marine life. Oceanogr Mar Biol Annu Rev 45:409-480

Rogers-Bennett L, Bennett WA, Fastenau HC, Dewes CM (1995) Spatial variation in red sea urchin reproduction and morphology: implications for harvest refugia. Ecol Appl 5:1171-1180

Rosenzweig C, Casassa G, Karoly DJ, Imeson A and others (2007) Assessment of observed changes and responses in natural and managed systems. In: Parry ML, Canziani OF, Palutikof JP, van der Linden PJ, Hanson CE (eds) Climate change 2007: impacts, adaptation and vulnerability. Contribution of Working Group II to the 4th Assessment Report of the Intergovernmental Panel on Climate Change. Cambridge University Press, Cambridge, p 79-131,

> Rowley RJ (1989) Settlement and recruitment of sea urchins (Strongylocentrotus spp.) in a sea-urchin barren ground and a kelp bed: Are populations regulated by settlement or post settlement processes? Mar Biol 100:485-494

Rowley RJ (1990) Newly settled sea urchins in a kelp bed and urchin barren ground: a comparison of growth and mortality. Mar Ecol Prog Ser 62:229-240

> Scheffer M, Carpenter S, Foley JA, Folke C, Walker B (2001) Catastrophic shifts in ecosystems. Nature 413:591-596

Steneck RS, Graham MH, Bourque BJ, Corbett D, Erlandson JM, Estes JA, Tegner MJ (2002) Kelp forest ecosystems: biodiversity, stability, resilience and future. Environ Conserv 29:436-459

Tegner MJ (1980) Multispecies considerations of resource management in southern California kelp beds. In: Pringle JD, Sharp GJ, Caddy JF (eds) Proc workshop on the relationship between sea urchin grazing and commercial plant/animal harvesting. Can Tech Rep Fish Aquat Sci 954:125-143

Tegner MJ, Dayton PK (1981) Population structure, recruitment and mortality of two sea urchins (Strongylocentrotus 
fransciscanus and $S$. purpuratus) in a kelp forest. Mar Ecol Prog Ser 5:255-268

Tegner MJ, Dayton PK, Edwards PB, Riser KL (1995) Sea urchin cavitation of giant kelp (Macrocystis pyrifera C. Agardh) holdfasts and its effects on kelp mortality across a large California forest. J Exp Mar Biol Ecol 191:83-99

Underwood AJ, Kingsford MJ, Andrew NL (1991) Patterns in shallow subtidal marine assemblages along the coast of

Editorial responsibility: Steven Morgan,

Bodega Bay, California, USA
New South Wales. Austral Ecol 16:231-249

Vasquez JA, McPeak RH (1998) A new tool for kelp restoration. Calif Fish Game 84:149-158

Wahle RA, Peckham SH (1999) Density-related reproductive trade-offs in the green sea urchin, Strongylocentrotus droebachiensis. Mar Biol 134:127-137

Walther GR, Post E, Convey P, Menzel A and others (2002) Ecological responses to recent climate change. Nature 416:389-395

Submitted: May 5, 2008; Accepted: September 5, 2008

Proofs received from author(s): December 16, 2008 